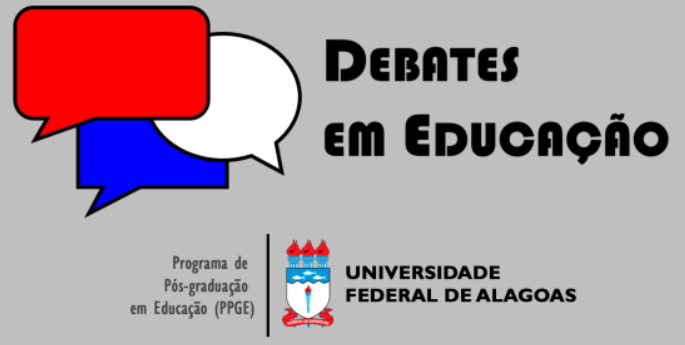

ISSN Eletrônico 2175-6600

Vol. 12 | Número Especial 2 | 2020

Emerson Pereira Branco

9 i

Universidade Estadual do Paraná (UNESPAR)

Secretaria de Estado da Educação e do Esporte do Paraná (SEED)

ems_branco@hotmail.com

Gisele Adriano

9 iD

Secretaria de Estado da Educação e do Esporte do Paraná (SEED)

giseleadriano@escola.pr.gov.br

Shalimar Calegari Zanatta

(9) iD

Universidade Estadual do Paraná (UNESPAR) shalicaza@yahoo.com.br

\section{EDUCAÇÃO E TDIC: CONTEXTOS E DESAFIOS DAS AULAS REMOTAS \\ DURANTE A PANDEMIA DA COVID- 19}

\section{RESUMO}

O presente artigo aborda o uso das Tecnologias Digitais de Informação e Comunicação (TDIC) na educação. Pesquisa o contexto social diante da pandemia causada pela COVID-19. O estudo é realizado por meio de análise bibliográfica e documental, considerando a legislação vigente. Objetivou evidenciar as possibilidades advindas da inserção dessas tecnologias diante da necessidade do distanciamento social e o cumprimento do calendário escolar. Para tanto, investigou as condições de acesso de professores e alunos às TDIC, a infraestrutura das escolas e o preparo dos professores para o letramento digital. Os resultados apontaram que os principais obstáculos se relacionam com a infraestrutura deficitária das instituições de ensino, falta de materiais e equipamentos tecnológicos, acesso restrito aos recursos tecnológicos e a necessidade de melhorar a formação inicial e continuada dos educadores.

Palavras-chave: Tecnologia. Formação docente. Pandemia.

\section{EDUCATION AND DICT: CONTEXTS AND CHALLENGES OF REMOTE CLASSES DURING THE COVID-I 9 PANDEMIC}

\section{ABSTRACT}

This paper addresses the use of Digital Information and Communication Technologies (DICT) in education. Research the social context in the face of the pandemic caused by COVID-19. The study is carried out by means of bibliographic and documentary analysis, considering the current legislation. It aimed to highlight the possibilities arising from the insertion of these technologies in view of the need for social distance and the fulfillment of the school calendar. To this end, it investigated the conditions of access of teachers and students to DICT, the infrastructure of schools and the preparation of teachers for digital literacy. The results showed that the main obstacles are related to deficient infrastructure of educational institutions, lack of technological materials and equipment, restricted access to technological resources and the need to improve the initial and continuing education of educators.

Keywords: Technology. Teacher education. Pandemic.

Submetido em: 29/07/2020

Aceito em: 13/09/2020

Publicado em: 30/12/2020

do http://dx.doi.org/I0.28998/2 I75-6600.2020v I 2nEsp2p328-350 


\section{INTRODUÇÃO}

Estamos diante de uma época marcada por grandes e rápidas transformações a partir da intensificação da utilização das Tecnologias Digitais da Informação e Comunicação (TDIC). Estas, aliadas à globalização, aceleraram as transformações na esfera social como um todo e de maneira surpreendente mudaram as formas de relacionamentos, comunicação, produção, consumo e de acesso à informação. Pensar a educação e o trabalho das instituições escolares, nesse contexto, é uma missão bastante complexa, porém imprescindível para garantir a efetividade das ações pedagógicas.

Condizente a esta ideia, Silva (2008) menciona que a tecnologia do século XX produziu, e continua a produzir, novas formas de sociedade e de cultura, alterando substancialmente os processos de valorização dos indivíduos, bem como os processos de produção da riqueza e de organização social.

Moreira e Kramer (2007) corroboram com a opinião de que a tecnologia nunca avançou tão rapidamente, e isto acarreta um desafio grandioso para os educadores. Além disso, a globalização tem afetado o modo de estruturar e de reorganizar a educação escolar, assim como o desenvolvimento do trabalho docente.

Para Martins (20/9), um dos aspectos desse desafio é estarmos diante de uma geração nascida num mundo onde as mídias digitais se popularizaram expressivamente. Dessa maneira, as pessoas agem e pensam de forma muito distinta de como pensávamos e agíamos na fase de escolarização. Criando a necessidade de escolher entre adaptar a educação para esse novo modelo de sociedade, a fim de atender as demandas sociais, ou manter uma educação considerada neste contexto como conservadora, baseando-se nos princípios tradicionais de organização e formação.

Segundo Altoé e Fugimoto (2009), as exigências quanto à educação tornam-se desafios do alinhamento das ações educacionais com a realidade social. Desse modo, aos profissionais da educação, é imposta a adoção de uma postura crítica e questionadora de sua própria prática, a fim de que a docência ocorra na interação entre a experiência, a tomada de consciência e, é claro, de novas sistemáticas de ensino provenientes de abordagens diferenciadas envolvendo o uso das tecnologias.

Nesta visão, a educação não deve distanciar-se da realidade na qual o aluno está inserido, porém são necessários fomentos e estruturas capazes de proporcionar aos profissionais usufruírem de novas técnicas e estratégias metodológicas mais atrativas e historicamente contextualizadas, repensando o fazer pedagógico de modo a superar por meio do uso das TDIC práticas pouco efetivas ou descontextualizadas.

A escola é de fato um ambiente privilegiado de interação social, e neste contexto, necessita interligar-se e integrar-se aos demais espaços de conhecimento hoje existentes. Incorporar as TDIC às práticas pedagógicas pode permitir que professores e alunos realizem maior correlação entre os 
conhecimentos, corroborando para a transformação, cooperação e contribuindo para o desenvolvimento do fazer pedagógico. Para muitos professores e equipes gestoras, os desafios que se apresentam à escola precisam ser encarados, tendo nas TDIC importantes meios para proporcionar mais dinamicidade e qualidade no processo de ensino e aprendizado.

E em especial diante do momento histórico vivenciado com a pandemia da COVID-19, no qual o distanciamento social foi necessário. Assim, evidenciou-se a necessidade praticamente imediata da utilização das TDIC como a possibilidade da manutenção das aulas, ainda que de forma remota. Neste contexto, foi imprescindível pensar em outras formas de promover o atendimento aos alunos de maneira não presencial, utilizando-se de momentos síncronos e assíncronos para o trabalho com os conteúdos e a interação entre professores e alunos.

Pretende-se desse modo, com base na análise de dados de pesquisas documentais como as legislações e revisão bibliográfica fomentar discussões sobre o uso das TDIC na educação. Evidenciando suas possibilidades e potencialidades pedagógicas, condições presentes nas escolas, assim como as necessidades e entraves para o uso efetivo por profissionais e alunos em todo o país, principalmente diante do contexto da pandemia causada pela COVID-19.

\section{ACESSO E UTILIZAÇÃO DAS TDIC NO BRASIL}

Os avanços tecnológicos impulsionaram mudanças na sociedade e no modo de viver das pessoas. Consequentemente a educação também vem sofrendo modificações devido ao surgimento de novas ferramentas como as TDIC, assim como, o próprio perfil dos alunos.

É importante destacar que embora os avanços tecnológicos venham ocorrendo de forma exponencial, sobretudo nas últimas décadas, esses recursos nem sempre chegam, ou estão disponíveis para todas as classes sociais ou indivíduos. A internet, por exemplo, um recurso básico e essencial em um mundo cada vez mais digital, não está presente em todos os domicílios brasileiros, o que também provoca influências na educação.

gráfico da Figura I, elaborado com base na Pesquisa Nacional de Amostra de Domicílios (PNAD), de 2019, do Instituto Brasileiro de Geografia e Estatística (IBGE), evidencia as desigualdades de acesso à internet em todo o país. Dessa forma, mais de 20,0\% dos domicílios do país ainda não possuem este recurso. Nas Regiões Norte e Nordeste a situação é ainda mais crítica, sendo que cerca de 30,0\% dos domicílios ainda não contam com este serviço. 
Figura I. Domićlios em que havia utilização da internet, por situação do domicílio.

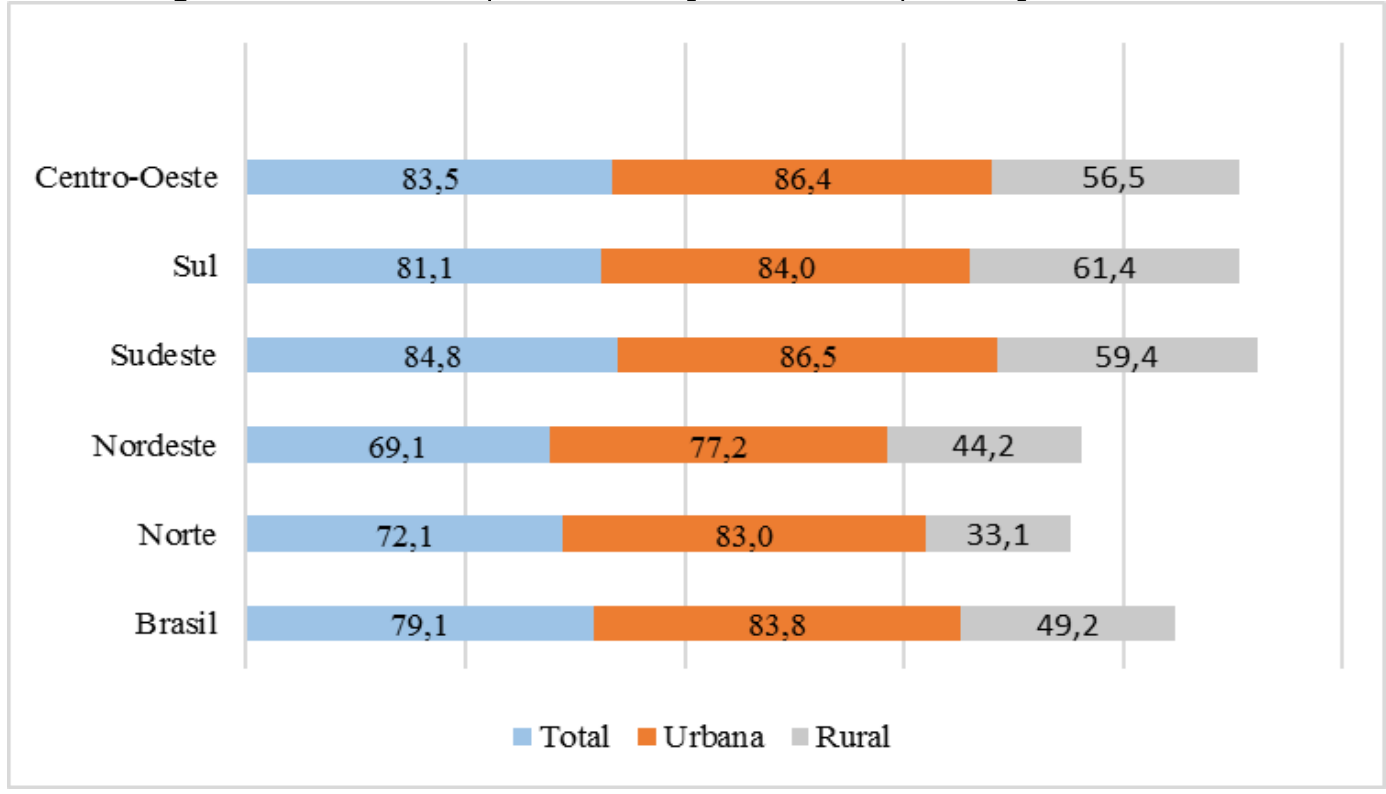

Fonte: IBGE (2020).

A Figura I também mostra que na zona rural o número de acesso é muito inferior comparado com a zona urbana, de forma que mais da metade dos domicílios do meio rural não dispõe do serviço. Tal situação demonstra a falta de assistência e investimentos para essas populações.

De acordo com Viero e Silveira (20l I), embora nas últimas décadas o meio rural tenha sofrido profundas alterações na sua configuração, os esforços governamentais têm-se mostrado insuficientes e excludentes, uma vez que a maior parte da população brasileira que vive no meio rural ainda não tem acesso a tecnologias como a internet. Para as autoras, isso se deve ao investimento tardio, e ainda escasso, no meio rural. Soma-se a isso a ausência de políticas públicas dirigidas à inclusão digital, o que pode comprometer o incremento da população rural à inclusão digital e, consequentemente, o desenvolvimento econômico e a própria permanência das novas gerações nesse espaço.

O gráfico apresentado na Figura 2, também resultante da PNAD de 2019, traz os motivos pelos quais os domićlís não têm acesso à internet. O principal motivo, tanto no meio rural, quanto no urbano é a falta de interesse. Contudo, cerca de 50,0\% dos domicílios sem o serviço, não o tinham por ser caro ou por falta de conhecimento de como usá-lo. Além disso, na zona rural em 20,8\% o serviço era indisponível, contra apenas I,0\% da zona urbana, o que comprova a falta de investimento na zona rural.

No campo educacional o uso de tecnologias digitais, sobretudo as TDIC, ainda não é uma realidade em todas as escolas públicas do país. Muitos são os desafios a serem superados, especialmente, no que diz respeito à infraestrutura das instituições escolares, à disponibilidade de equipamentos e recursos tecnológicos, além de formação inicial e continuada dos profissionais da educação capazes de contribuir para o advento de novas práticas metodológicas com base nas TDIC. 
Figura 2. Domicilios em que não havia internet por motivo de não utilização - Brasil - 2018

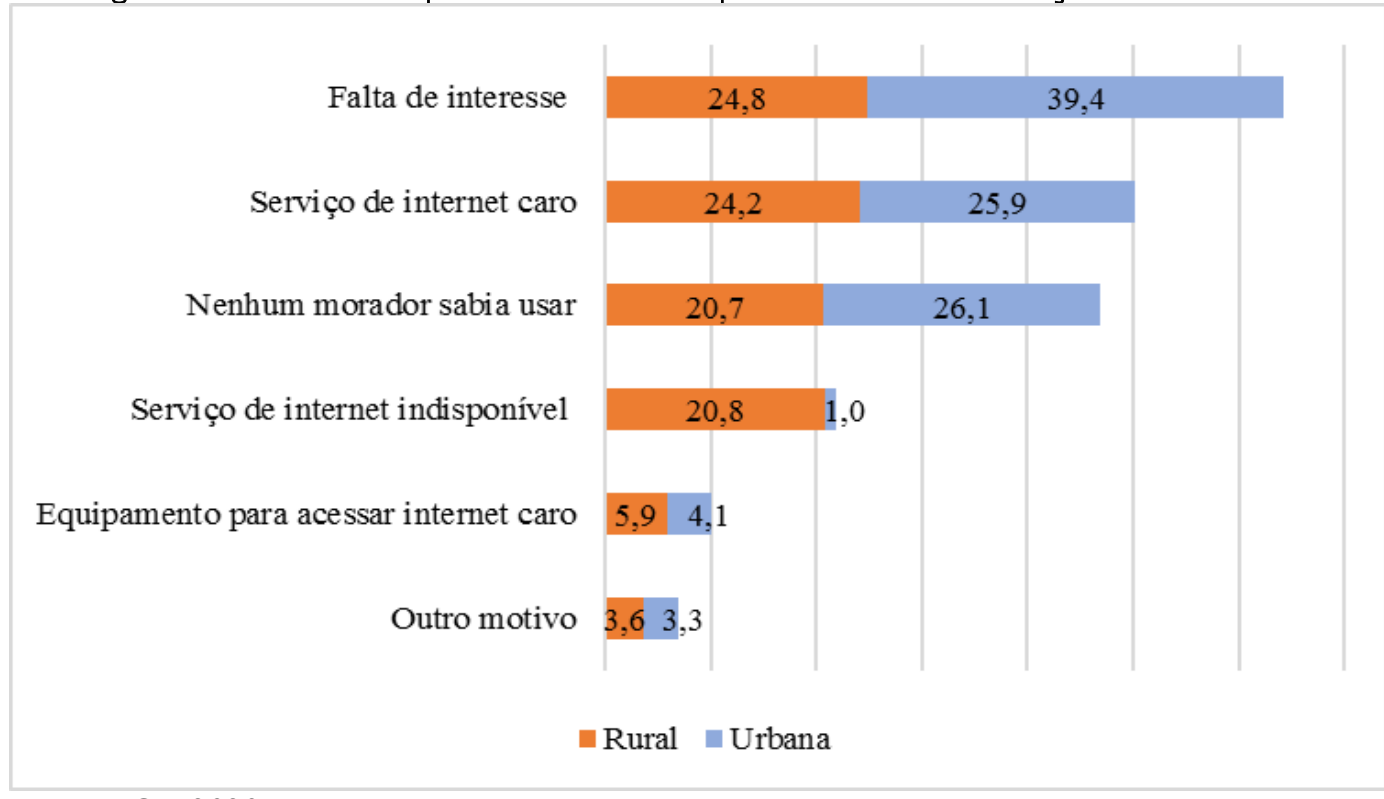

Fonte: IBGE (2020).

De acordo com o Censo Escolar da Educação Básica de 2019 realizado pelo Instituto Nacional de Estudos e Pesquisas Educacionais Anísio Teixeira (INEP), mais de 40,0\% das escolas de Ensino Fundamental, considerando as redes municipal, estadual, federal e privada, não possuem biblioteca ou sala de leitura. O laboratório de Ciências está presente em apenas 12,5\% dessas instituições.

Nas escolas de Ensino Médio, II,8\% não possuem biblioteca ou sala de leitura e 52,0\% não possuem laboratório de Ciências. Além desses, outros espaços importantes como quadra de esporte e laboratório de Informática também não são encontrados em grande parte das escolas, demonstrando que muitas são as carências de infraestrutura nas instituições escolares da Educação Básica.

Com relação aos recursos tecnológicos também há grandes demandas encontradas. Conforme pode-se observar na Figura 3 a internet está ausente em boa parte das instituições, principalmente na sua utilização com fins pedagógicos.

Como se pode observar, os melhores índices são encontrados nas escolas da rede federal, sendo a presença da internet em I00,0\% para uso administrativo e 80,9\% para uso no processo de ensino e aprendizagem. As maiores carências estão nas escolas da rede municipal, de forma que 58,2\% das escolas possuem o recurso para fins administrativos e apenas 29,6\% para fins pedagógicos. 
Figura 3. Internet disponível nas escolas segundo dependência administrativa - Brasil - 2019

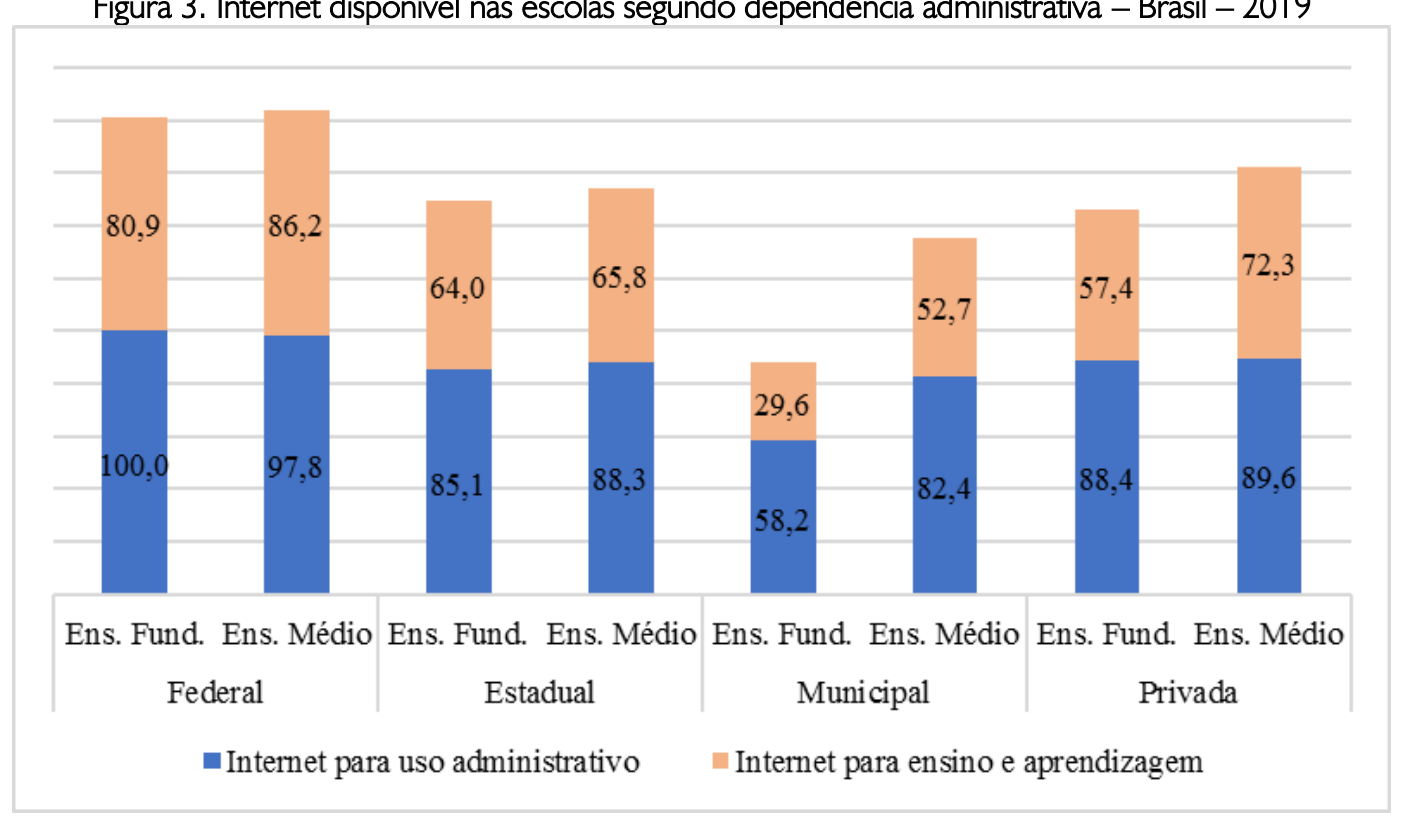

Fonte: Elaborado pelos autores com base nos dados do INEP (2020).

A disponibilidade de outros recursos tecnológicos como lousa digital, projetores multimídia e computadores para uso dos alunos está representada na Figura 4. A exemplo da internet, novamente os melhores índices foram encontrados nas escolas da rede federal e os piores na rede municipal de ensino. Considerando os recursos representados, os mais encontrados foram o projetor multimídia, presente em mais de $90,0 \%$ das escolas da rede federal; cerca de $80,0 \%$ na rede estadual e mais de $70,0 \%$ da rede privada; e o computador de mesa presente em aproximadamente $90,0 \%$ das escolas da rede federal e cerca de $75,0 \%$ da rede estadual.

Figura 4. Recursos disponíveis nas escolas segundo dependência administrativa - Brasil - 2019

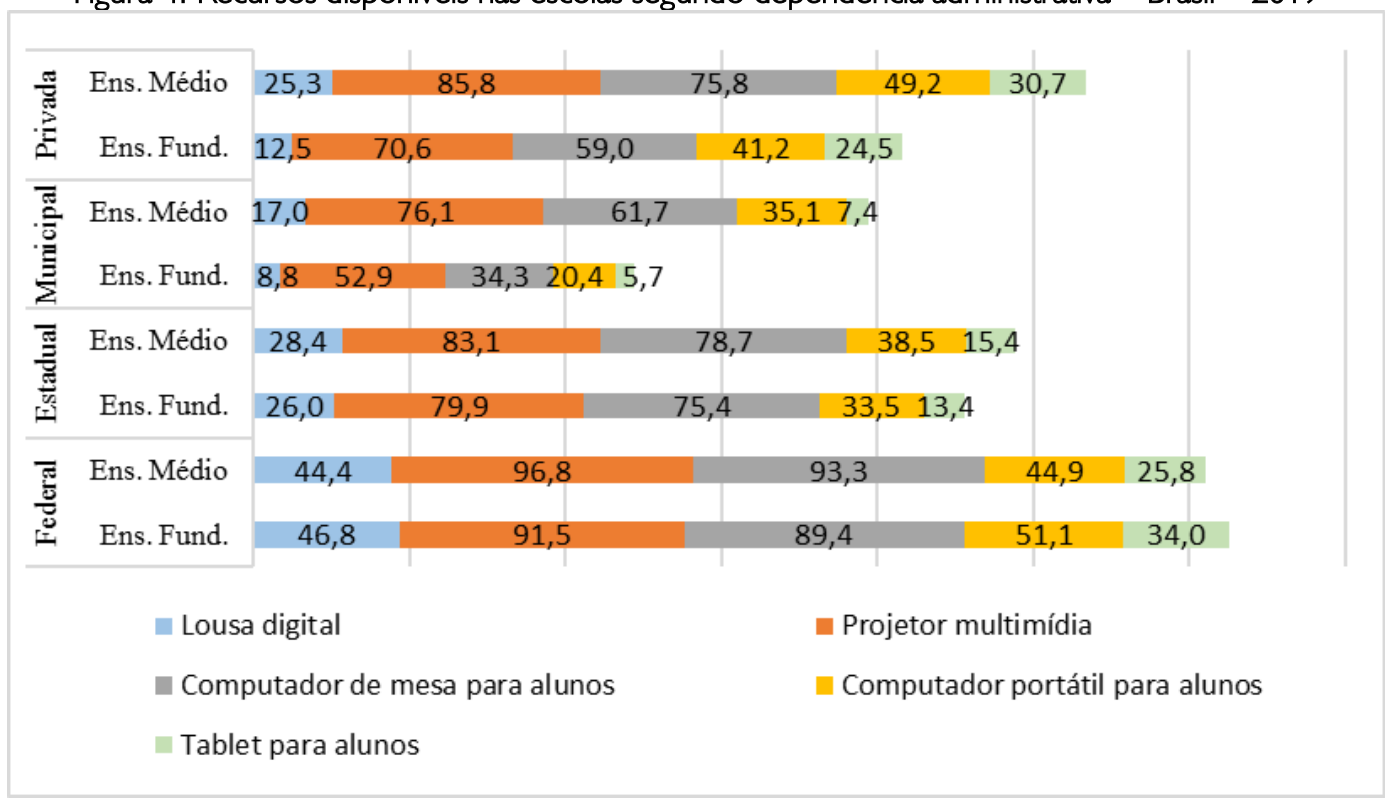

Fonte: Elaborado pelos autores com base nos dados do INEP (2020). 
Diante dessa realidade, observa-se que, embora as TDIC representem importantes meios para agregar mais qualidade à educação, são necessários maiores investimentos na infraestrutura e na compra de recursos tecnológicos para que professores e alunos possam utilizar esses recursos no processo de ensino e aprendizagem.

A esse respeito Valente (2018) destaca que embora a maior parte dos diferentes segmentos da sociedade já possa ser considerada como parte da cultura digital, a educação continua sendo um setor que ainda precisa avançar muito para fazer efetivamente parte dessa cultura. Segundo Altenfelder et al (20I I), a cultura digital relaciona-se aos conceitos de cibercultura e era digital. Refere-se à cultura decorrente dos usos da internet e outros aparatos digitais que intermedeiam as relações e as produções humanas, favorecendo trocas e interações entre as pessoas e novos modelos de aprendizagem e meios de expressão.

Segundo Caetano (20 I5), o uso dos recursos tecnológicos nas atividades pedagógicas possui um potencial motivador. Vale lembrar que a ausência de motivação é uma realidade que interfere na qualidade das aprendizagens. Desse modo, as tecnologias podem contribuir para melhorar os níveis de motivação e a concentração dos alunos, além de ajudar na organização, favorecer o empenho e a participação, proporcionando mais interesse pelo trabalho desenvolvido em sala de aula.

Cabe destacar que, no Brasil, os índices de reprovação, evasão e abandono são ainda muito preocupantes. Investir e equipar melhor a escola pode contribuir significativamente para atender o novo perfil do alunado, para a melhoria da qualidade educação e, consequentemente, favorecer a luta contra a evasão e o abandono.

É necessário ressaltar que o mundo está cada vez mais digital e repensar a organização escolar, no sentido de favorecer o letramento digital, capacitando os alunos e professores para maior domínio das TDIC, e das várias mídias digitais, faz parte dos novos desafios contemporâneos da educação. Acerca do letramento digital, Bezerra, (20l8) define-o como mais uma atividade em que os sujeitos poderão fazer uso dos conteúdos informacionais por meio da utilização das TDIC.

A esse respeito Caetano destaca que,

Os recursos tecnológicos lançam vários desafios na educação, nomeadamente, ao nível do acesso à informação, na diversidade de meios, nos tipos de aprendizagem, nos tipos de comunicação e no novo perfil de alunos e professores. É reconhecido o fato de a tecnologia ter um papel fundamental no acesso à informação, permitindo que, quase em qualquer lugar, seja possível consultar documentos digitais sobre várias temáticas reduzindo o mundo e quebrando fronteiras. Para além disso, importa realçar que os processos de aprendizagem foram alvo de profundas alterações nos contextos onde a tecnologia passou a estar presente colocando, por exemplo, o aluno como criador de conhecimento através de uma maior autonomia no acesso à informação (CAETANO, 2015, p. 306).

Diante desse cenário, dos desafios para a educação, frente a chamada cultura digital, há que se refletir sobre o papel da escola, na superação das demandas por melhor infraestrutura e na disponibilidade 
de mais recursos tecnológicos para uso pedagógico. Consoante, faz necessário melhorar o processo de formação inicial, assim como a formação continuada, dos professores, com vistas a estarem melhor preparados para o novo perfil dos alunos e do uso das mídias digitais e das TDIC na educação.

\section{A IMPORTÂNCIA DA FORMAÇÃO DOCENTE PARA O USO DA TECNOLOGIA NA PRÁTICA PEDAGÓGICA}

De acordo com Moreira e Kramer (2007), a globalização tem influenciado no modo de estruturar a educação escolar e de desenvolver o trabalho docente. Esse processo está inserido na revolução científico-tecnológica e no advento das TDIC na sociedade, cujos reflexos também estão presentes na sala de aula.

Barreto (2004) ressalta que a popularização das TDIC promove, ainda que de forma indireta, um movimento de reconfiguração do trabalho e da formação docente. É preciso destacar que a presença das TDIC têm sido cada vez mais constante no discurso e nas atividades pedagógicas, compreendido como o conjunto das práticas de linguagem desenvolvidas no processo de ensino.

Nesse horizonte, para que os professores sejam melhor preparados para lidar com tantas mudanças, com os avanços tecnológicos, com as novas mídias e com o perfil dos alunos que vem mudando constantemente é importante repensar e investir mais na formação inicial e na formação continuada. Contudo, no cenário brasileiro ainda há desafios mais básicos que não foram superados, como garantir que todos profissionais tenham curso superior e licenciatura específica para as disciplinas que lecionam.

O Censo Escolar da Educação Básica de 2019 realizado pelo Instituto Nacional de Pesquisas Educacionais Anísio Teixeira (INEP) revelou que, no Brasil, apenas 63,3\% dos professores de Ensino Médio e 60,2\% do Ensino Fundamental possuíam formação na mesma área das disciplinas que lecionavam. Dessa forma, pelo menos I em cada 3 professores da Educação Básica atuava sem formação específica em 2019, Figura 5. 
Figura 5. Percentual de disciplinas ministradas por professores com licenciatura na mesma área de atuação - Brasil - 2019

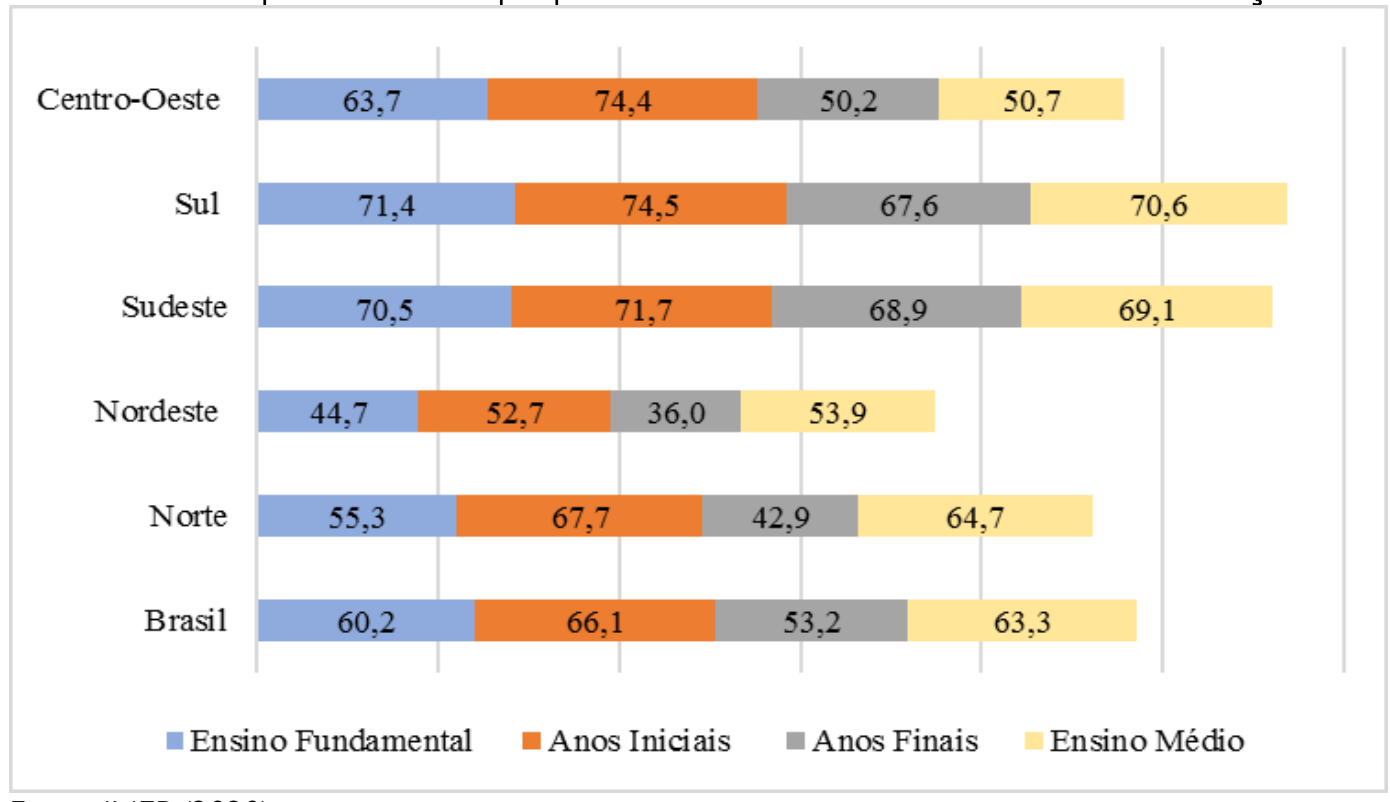

Fonte: INEP (2020).

Na Região Centro-Oeste apenas 50,7\% dos professores do Ensino Médio tinham a formação superior na mesma área de atuação. Na Região Norte o índice era de 55,3\% para os professores de Ensino Fundamental e na Região Nordeste 44,7\%, para a mesma etapa de ensino. Os dados evidenciam o quanto o Brasil precisa evoluir em termos de formação inicial do professor, no sentido de garantir a formação mínima específica.

Diante dessa realidade torna-se compreensível o fato de que pouco se tem avançado na utilização das TDIC no âmbito do trabalho pedagógico. É difícil vislumbrar um cenário de formação inicial e continuada de professores que atenda esta demanda, quando sequer foi alcançado o objetivo de universalizar uma formação mínima adequada, conforme estabelece a Lei de Diretrizes e Bases da Educação (LDB).

Para Valente (20|8), as requeridas mudanças no sistema educacional, especialmente no que se refere no uso da TDIC, não podem ficar restritas somente ao contexto da sala de aula ou do aspecto pedagógico. É preciso repensar toda estrutura e fatores que dão suporte ao que acontece nessa nova sala de aula, inclusive a formação de professores.

Nessa perspectiva, é vital a discussão sobre a formação inicial que proporcione ao profissional conhecimento e condições de estar preparado para atuar com essas novas questões. Sobre esse aspecto Caetano considera que:

As escolas, os professores e os alunos passaram a ter novas formas de comunicar. Atualmente, a tecnologia coloca a sala de aula nos mais variados ambientes virtuais e possibilita que a "escola" possa assumir novas formas e novos espaços. Mas a integração da tecnologia na educação só será uma realidade se os professores forem reais atores da mudança e estiverem formados técnica e pedagogicamente. Aliás os professores são um dos principais fatores de sucesso dos projetos de integração da tecnologia (CAETANO, 2015, p. 307). 
Em certo sentido parece evidente que sem uma formação inicial sólida para os professores que contemple tanto as questões e os saberes pedagógicos, quanto as questões técnicas, incluindo as TDIC, não ocorrerão avanços significativos na utilização desses recursos no processo de ensino e aprendizagem.

Tarouco (2019) afirma que somente por meio de uma formação que contemple satisfatoriamente o uso dessas ferramentas os professores poderão explorar plenamente o potencial das TDIC. Para a autora, deve-se contemplar e delinear estratégias para orientar a formação de professores e o desenvolvimento profissional contínuo, e contribuir para a melhoria do processo de ensino e aprendizagem, ofertando aos alunos conhecimentos essenciais para a vida e para o trabalho em uma sociedade cada vez mais digital.

Consoante, Moreira (20I2) acredita que as TDIC podem contribuir muito para o trabalho do professor na sala de aula. Assim, investir nesse profissional desde a sua formação inicial até a continuada, é fundamental para que ele possa aperfeiçoar as metodologias e a aprendizagem dos alunos, por meio das TDIC.

Vale lembrar que a formação inicial, em especial, das licenciaturas pode passar por modificações nos próximos anos, frente a implantação da Base Nacional Comum Curricular (BNCC). Considerando que, em consonância com a BNCC, a Lei n 13.4I5/2017 estabelece, em seu Art. 7, que "os currículos dos cursos de formação de docentes terão por referência a Base Nacional Comum Curricular" (BRASIL, 2017).

Nesse horizonte, as mudanças que as licenciaturas podem sofrer estão relacionadas à questão de organização curricular, uma vez que a BNCC será a referência, e até mesmo na própria existência de alguns cursos, pois a Lei n 13.4I5/2017 define que: "A Base Nacional Comum Curricular referente ao ensino médio incluirá obrigatoriamente estudos e práticas de educação física, arte, sociologia e filosofia" (BRASIL, 2017, grifos nossos).

Branco et al (20 I 8) afirmam que, embora a Lei n 13.4I 5/2017 estabeleça que Apesar Educação Física, Arte, Sociologia e Filosofia serão incluídas obrigatoriamente no ensino médio, não menciona se será no formato de disciplina, cita apenas "estudos e práticas", o que não deixa de ser preocupante. Assim, essas disciplinas poderiam ser incorporadas nas quatro grandes áreas de conhecimento definidas pela BNCC, podendo ser agregadas a outras disciplinas, o que poderia implicar até mesmo na extinção de cursos de licenciaturas. Vale ressaltar que, de acordo com a referida Lei, somente Língua Portuguesa e Matemática serão obrigatórias nos três anos do ensino médio.

Cabe frisar que a BNCC que é um documento de caráter normativo para a Educação Básica em nível nacional foi aprovada em duas etapas pelo Conselho Nacional de Educação (CNE), sendo, em 2017 , a parte referente a Educação Infantil e o Ensino Fundamental e, em 20 I8, a do Ensino Médio. 
É importante destacar que a BNCC foi formulada de modo a apresentar as aprendizagens essenciais para a Educação Básica. A Base foi elaborada tendo como objetivo garantir aos alunos o desenvolvimento de dez competências gerais, que de acordo com o documento "consubstanciam, no âmbito pedagógico, os direitos de aprendizagem e desenvolvimento" (BRASIL, 20।8, p. 8).

No que se refere às tecnologias, a BNCC estabelece na competência de número 5 que:

Compreender, utilizar e criar tecnologias digitais de informação e comunicação de forma crítica, significativa, reflexiva e ética nas diversas práticas sociais (incluindo as escolares) para se comunicar, acessar e disseminar informações, produzir conhecimentos, resolver problemas e exercer protagonismo e autoria na vida pessoal e coletiva (BRASIL, 20।8, p. 9. Grifos nossos)

Em concordância com a competência 5, o documento também menciona a importância para os alunos, como cidadãos em formação, de conhecerem e aplicarem as TDIC em seu contexto familiar e cultural. Além disso, explicita como essas tecnologias são importantes para a aprendizagem, dentro e fora da escola, e para o convívio e interação social. Assim, a BNCC menciona que:

As experiências das crianças em seu contexto familiar, social e cultural, suas memórias, seu pertencimento a um grupo e sua interação com as mais diversas tecnologias de informação e comunicação são fontes que estimulam sua curiosidade e a formulação de perguntas. $\bigcirc$ estímulo ao pensamento criativo, lógico e crítico, por meio da construção e do fortalecimento da capacidade de fazer perguntas e de avaliar respostas, de argumentar, de interagir com diversas produções culturais, de fazer uso de tecnologias de informação e comunicação, possibilita aos alunos ampliar sua compreensão de si mesmos, do mundo natural e social, das relações dos seres humanos entre si e com a natureza (BRASIL, 2018, p. 58)

Diante do exposto, verifica-se que há uma necessidade e uma intencionalidade no que se refere ao uso das TDIC tanto por alunos como por professores. Observa-se também que há uma percepção de que é necessário repensar a formação inicial dos professores, ampliando e qualificando melhor os cursos de licenciatura, sobretudo na questão do uso pedagógico das TDIC. Todavia, pouco se tem avançado nesse sentido, e as medidas necessárias pouco caminham na prática de formação docente.

Freitas (20 I0), ao analisar a ementa de cursos de formação docente e a relação com as TDIC, afirma que a parte curricular dos cursos de licenciatura, que propicia, ou que deveria proporcionar, o desenvolvimento de conhecimentos específicos para a atuação nas escolas e nas salas de aula, se apresenta muito reduzida. Para a autora, mesmo nos cursos onde a temática é abordada, fica mais restrita à teoria, não chegando à prática. Estuda-se sobre as TDIC na educação, mas não se forma o futuro professor envolvendo-o em atividades de efetivo uso desses recursos como instrumentos de aprendizagem.

Assim, até há uma preocupação em abordar temas relacionados com a tecnologia nos cursos de formação inicial, mas ainda não se consegue proporcionar a prática e os conhecimentos para o professor em formação.

Conforme mencionam Prado e Rocha (2018), é necessário rever a formação docente, considerando as características da sociedade atual e as demandas por profissionais da educação que 
dominem essas novas ferramentas, que se apropriem e façam uso pedagógico das TDIC na perspectiva de integrá-las ao currículo da escola, ao seu contexto e às realidades dos alunos.

Cabe ressaltar que se por um lado é preciso repensar a formação inicial dos professores que ingressarão na Educação Básica, por outro é preciso refletir sobre a formação continuada dos professores que já atuam.

É preciso acentuar que, de acordo com Carvalho (2018), em 2017, a média de idade do professor da Educação Básica era de 4I anos de idade. Deste modo, pode-se inferir que a maioria dos professores que lecionam são formados a pelo menos 15 anos. Se atualmente a graduação ainda não contempla satisfatoriamente o uso das TDIC, a 15 anos, provavelmente, era ainda mais deficitária nesse sentido. Reside nesse cenário a necessidade por formação continuada, com vistas a capacitar os profissionais da educação para a utilização das TDIC.

Entretanto, como afirmam Libâneo, Oliveira e Toschi (2012) no tocante à formação continuada, há vários dilemas relacionados à necessidade de promover mudanças nos conceitos e nas práticas profissionais e pessoais dos professores. Estes por sua vez, encontram muitas dificuldades para se tornarem melhores profissionais. Para os autores, a formação continuada engloba: ações de formação durante a jornada de trabalho, por meio de reuniões, trocas de experiências, discussão de práticas e estratégias, pesquisas, minicursos, estudo de caso, entre outros; e ações de formação fora da jornada de trabalho, como cursos, encontros, palestras, entre outros.

Nessa perspectiva, a formação continuada é a garantia de desenvolvimento profissional permanente, sendo responsabilidade tanto da instituição como do próprio profissional. Libâneo, Oliveira e Toschi (20 I2), também consideram que alguns fatores dificultam a formação continuada como: muitos professores terem concepções, percepções, significados e esquemas de ação já consolidados, em decorrência de sua formação inicial e de sua cultura profissional; estereótipos consolidados em relação às diferenças psicológicas e sociais entre alunos; fatores externos à escola, sobretudo aqueles relacionados às características sociais e culturais; despreparo profissional, que pode estar associado à frágil formação inicial, envolvendo tantos saberes pedagógicos como outros saberes específicos, como o conhecimento da aplicação de TDIC na educação.

Dessa forma, é preciso considerar essas realidades para o planejamento de ações que promovam uma melhor formação continuada dos professores, para garantir os conhecimentos mínimos para que a prática docente assuma contornos com maior qualidade, por meio de novas metodologias.

No entanto, para que o professor possa reconstruir o conhecimento [...] de tal forma que possa integrar as tecnologias digitais ao currículo, é preciso compreender, inicialmente, como se dá o seu processo de apropriação tecnológica no contexto da escola. Esse processo não é simples; muitas vezes, demanda de o professor revisitar concepções pedagógicas, aprofundar conceitos e apropriar-se dos recursos tecnológicos presentes no contexto da escola (PRADO; ROCHA, 2018, p. 153). 
De forma complementar Silva (2012) assegura que a formação continuada que objetiva a capacitação do professor para uso das tecnologias digitais nas aulas deve ir além da mera instrumentalização do professor. Deve proporcionar uma formação reflexiva e crítica diante do uso das TDIC na atividade docente.

Nesse sentido, o professor não deve ser um mero instrutor ou aplicador de tecnologias, simplesmente por ser uma tendência, mas usá-las como complemento, como forma de enriquecimento das atividades pedagógicas, como meio de maior interação com o aluno, a fim de dar mais qualidade e mais significado às aulas. Assim, a formação continuada deve conferir os conhecimentos necessários sobre a utilização das TDIC, contudo, sem que os conteúdos sejam relegados a um segundo plano, sem que o professor seja secundarizado, e de forma que permaneça como um educador que instigue a reflexão, a criticidade e a criatividade do aluno, conferindo-lhe um caráter de cidadão que busque sua emancipação social.

Portanto, como assevera Oliveira (20I5, p. 132) o bom emprego das TDIC no âmbito escolar "depende do uso dos conhecimentos ainda precários a respeito de como as pessoas interagem e aprendem com essas tecnologias". Depende também, e muito, de como os professores são capacitados, tanto na formação inicial como na continuada. Por meio de formação de qualidade os professores serão capazes de fazer uso adequado das TDIC, sem subaproveitamento das tecnologias disponíveis, sem perder sua relevância e de forma a garantir que os alunos aprendam o que de fato é importante para suas vidas.

\section{TDIC E AULAS NÃO PRESENCIAIS: O CASO DA PANDEMIA DA COVID-I 9 EM 2020}

Com a pandemia causada pela COVID-19 o isolamento social foi determinado em todo o território nacional, consequentemente, muitas empresas tiveram suas atividades suspensas, assim como as aulas da Educação Básica e do Ensino Superior. Deste cenário despontam impactos econômicos, sociais e culturais significativos para sociedade. Pode-se dizer ainda, que este foi um evento ímpar, visto que, no passado apesar das graves epidemias que acometeram a sociedade, nada se compara aos recentes episódios, pois o cenário mundial não foi afetado diretamente e em tão larga escala. No entanto, atualmente o mundo é mais globalizado e com outras características de densidade populacional, onde a circulação de pessoas é muito maior, e consequentemente, a veiculação do vírus também.

Para amenizar os impactos já identificados, ações emergenciais foram tomadas nacionalmente com relação aos trabalhadores, em especial, aqueles que ficaram sem renda, mediante a disponibilização de um auxílio financeiro pelo Governo Federal. Já na educação, com as aulas presenciais suspensas a partir da possibilidade dada pelo Parecer 05/20 CP/CNE de 28 de abril (BRASIL, 2020a), e depois 
complementado pelos pareceres 09/20 CP/CNE (BRASIL, 2020b) e I I/2020 CP/CNE de 06 de junho e 07 de julho, (BRASIL, 2020c), respectivamente, muitas instituições passaram a disponibilizar aulas não presenciais, utilizando a internet e recursos tecnológicos para não comprometer ainda mais o ano letivo de 2020.

Tanto a ação do Governo para disponibilizar os recursos financeiros para os trabalhadores impossibilitados de trabalhar, quanto à ação das instituições de ensino de ofertar aulas não presenciais tiveram, basicamente, o mesmo problema: a falta, ou a não universalidade, do acesso à internet e a outros recursos tecnológicos, como a posse de um smartphone. Tal situação revela o quanto o país ainda carece de políticas que favoreçam o acesso às tecnologias, sobretudo, das famílias menos favorecidas financeiramente.

De acordo com Almeida (20।8), o processo natural de reestruturação social provocado, dentre outras coisas, pelo espaço-tempo da cultura digital interfere não apenas nas relações e ações humanas, assim como nas instituições, mas também no próprio conhecimento. Isso exige da escola, instituição que se pauta pelo trabalho com o conhecimento sistemático e historicamente organizado, um processo drástico de reestruturação e de ressignificação do currículo.

Nesse cenário, ressignificação e reestruturação se tornaram não apenas possibilidades, mas caminhos necessários a serem trilhados, diante da pandemia da COVID-19. Tal situação, por motivos de precauções com a saúde, levou governantes a suspender, entre outras atividades, as aulas presenciais de milhões de alunos em todo país e a buscar por meio do uso das TDIC uma forma de continuar a atender os alunos.

No entanto, não só o currículo precisou ser revisto, mas também o papel do professor com a utilização das ferramentas digitais. Como aponta Lévy (1999), o foco não pode ser apenas a difusão do conhecimento, mas também a competência de incentivar o pensamento e a aprendizagem colaborativa assistida pelo computador ou smartphone. Essas ações relacionam-se também ao uso dos chamados ambientes virtuais de aprendizagens adotados por diversas instituições.

A emergência da reformulação estrutural das escolas para atendimento dos alunos perante a pandemia trouxe consigo, a necessidade quase que instantânea de uma mutação com relação ao saber e as práticas pedagógicas. Apontando mais do que nunca, a necessidade de trabalhar não apenas com o ensino massificado, costumeiramente feito presencialmente. Ou seja, ao mesmo tempo e da mesma maneira para todos. Mas um ensino personalizado, considerando condições de acesso, domínio das ferramentas, rotinas de estudo e que ocorre muitas vezes de maneira assíncrona.

É preciso reconhecer que mudanças dessa natureza não são fáceis de serem implantadas. As incertezas em termos do ritmo e extensão com que a sociedade muda, dos avanços tecnológicos e das novas exigências educacionais podem ser paralisantes. Isso porque, tanto professores, quanto alunos 
precisam apresentar o mínimo de letramento digital, isto é, conhecimento necessário para saber como usar os recursos tecnológicos e a escrita no meio digital, para, dessa maneira, conseguir desenvolver ou acompanhar as aulas. Porém, a implantação aligeirada diante do cenário de pandemia não permitiu uma preparação, começando a ocorrer muitas vezes de forma improvisada. Alunos e professores aprendendo no próprio percurso.

Entretanto, continuar como antes ou ficar sem promover acesso algum à educação durante a pandemia, poderia ser ainda pior, como assevera Valente (20I8), pois possivelmente isso beneficiaria os que menos precisam, os que já sabem lidar e utilizar-se das TDIC.

Há que se convir que é impossível admitir que o preparo dos cidadãos para estas tecnologias acontecerá apenas com a disponibilidade e acessibilidades aos recursos existentes. Sem o empenho das instituições de ensino inseridas na cultura digital os impactos sociais, econômicos e as desigualdades sociais poderão ser ainda maiores.

Cabe frisar que os indivíduos com acesso às mídias digitais e internet, normalmente já possuem meios de adquirir as informações e conhecimentos. Porém, os que não possuem continuarão a ficar à margem do processo, dependentes do repasse das informações e conhecimentos. E, desse modo, tendo limitadas suas possibilidades quanto ao protagonismo na produção do próprio conhecimento e autonomia intelectual.

Conforme salienta Baranauskas (20|8), a tecnologia digital transformou a maneira como interagimos, nos comunicamos e vivemos em sociedade. A escola, como instituição e organização social, não pode ausentar-se dessas transformações. Visto que em muitos casos, pode ser o único mecanismo para promover o acesso e o letramento digital dos alunos.

Almeida (20 I 8) destaca que o currículo da cultura digital está interligado com outras culturas, no sentido de contribuir e transformar as maneiras de pensar, interagir, produzir e atribuir significado ao conhecimento e às relações. Essa possibilidade criada pelas TDIC acaba por promover as interações multidirecionais e não apenas hierárquicas, a emancipação na seleção de informações de diferentes fontes, a construção colaborativa de conhecimentos nos ciberespaços, diferentes linguagens e culturas apresentadas em hiperconexões.

Se num primeiro momento como evidencia Cardoso (20 I I), a tecnologia trouxe-nos um modelo de comunicação em massa, agora mais do que nunca passamos a vivenciar um modelo de comunicação em rede. Neste contexto, observa-se ainda as características de baixa interatividade, voltado para pesquisa e navegação, assim como o crescimento da comunicação de alta interatividade, que pressupõe a criação e compartilhamento de produções e opiniões.

Prado e Rocha (20 I 8) consideram que a apropriação da tecnologia e sua utilização, sobretudo para fins pedagógicos, devem ocorrer em um processo gradativo, constituído por diferentes fases. Tais fases 
vão desde o conhecimento operacional e técnica dos recursos tecnológicos que caracterizam a adoção das tecnologias, passando por fases intermediárias de diversos tipos de adaptação, que envolve uso parcial das tecnologias, até chegar às fases da inovação e da integração.

No entanto, devido à urgência de implantação das aulas não presenciais, em decorrência à pandemia da COVID-19, na maioria das escolas, principalmente as que não tinham como usual a utilização de recursos tecnológicos nas práticas pedagógicas, não foi possível a passagem das fases supracitadas. Ainda que elas tenham ocorrido, em virtude da brevidade de tempo para planejamento, não ocorreram de maneira satisfatória, o que ocasionou muitas dificuldades para gestores, equipes pedagógicas, professores, alunos e famílias.

Assim sendo, muitos professores que tinham pouco ou nenhum contato com tecnologia passaram a planejar suas aulas intermediadas por aplicativos ou salas virtuais por intermédio das telas de computadores ou celulares, tudo isso ao mesmo tempo em que descobrem seu funcionamento. Assim como, os coordenadores pedagógicos passaram a acompanhar esta nova forma de interação entre professores e alunos, além de vivenciarem novos desafios como problemas de conexão à internet, engajamento dos alunos neste atendimento remoto, a falta de acesso e o conhecimento no uso das ferramentas digitais.

No mapa conceitual abaixo é possível identificar como as TDIC servem de aporte para as aulas não presenciais, pois se configuram no uso de novos recursos digitais que exploram diferentes linguagens e mídias. Contudo, evidencia algumas das dificuldades quanto à implementação do uso das TDIC nas escolas por professores e alunos para as aulas não presenciais.

Figura 6. Mapa conceitual correlacionando TDIC às aulas não presenciais e às dificuldades encontradas

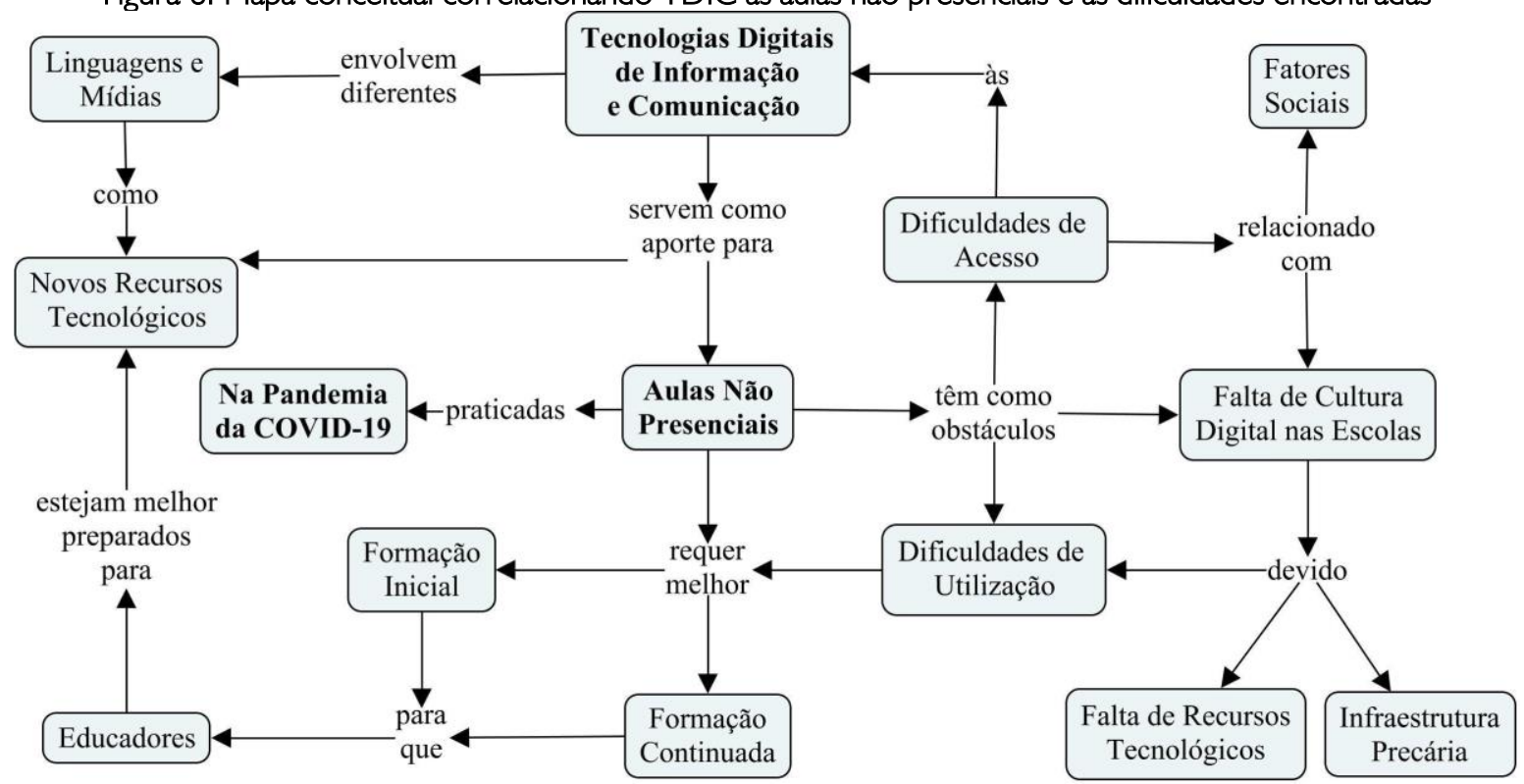

Fonte: Elaborado pelos autores (2020). 
Notam-se a presença das dificuldades de acesso e utilização advindas da ausência de cultura digital das escolas, isso em virtude da falta de recursos tecnológicos e infraestrutura, como já apontado nas Figuras 3 e 4. Assim como, destaca-se os fatores sociais das famílias, neste caso financeiros e culturais, que privam muitos de terem a possibilidade de utilizar os recursos e o acesso à internet para o acompanhamento das aulas.

Sobre a utilização por parte dos professores, identifica-se a fragilidade existente na formação inicial, de forma que a maioria dos que estão lecionando atualmente, não tiveram acesso a esses conceitos e conhecimentos em suas graduações, visto que esta exigência aparece normatizada pela primeira vez na Resolução CNE/CP n I, de 18 de fevereiro de 2002, que institui as Diretrizes Curriculares Nacionais para a Formação de Professores da Educação Básica, em nível superior, curso de licenciatura, de graduação plena (BRASIL, 2002). E recentemente previstos na Resolução CNE/CP n 2, de I de julho de 2015 (BRASIL, 20।5), assim como, na Resolução nº 2 de dezembro de 2019, esta última, articulada com a Base Nacional Comum Curricular:

Art. $8^{\circ}$ Os cursos destinados à Formação Inicial de Professores para a Educação Básica devem ter como fundamentos pedagógicos:

\section{$(\ldots)$}

IV - emprego pedagógico das inovações e linguagens digitais como recurso para o desenvolvimento, pelos professores em formação, de competências sintonizadas com as previstas na BNCC e com o mundo contemporâneo; (BRASIL, 2019, p. 5. Grifos nossos).

Desse modo, é notório que estes problemas foram intensificados ao longo destes anos, pois muitos professores não tiveram formação inicial para atuarem com esta demanda, ou se tiveram não foi com os resultados esperados. Por muito tempo, estas fragilidades acabaram por acarretar a negação da utilização dos recursos tecnológicos como instrumento da prática pedagógica pelos professores, que pela falta de conhecimento e/ou disponibilidade de acesso, por inúmeras vezes, só proibiam a utilização em sala de aula, não aproveitando suas potencialidades, a troca de experiências e as possibilidades de interação.

Estas situações implicam em limitar as possibilidades dos alunos terem nas escolas espaços de compartilhamento da utilização das tecnologias, na garantia de equidade quanto à participação ativa em sua própria trajetória acadêmica e não apenas restringindo esta viabilidade aos que possuem acesso fora dela. Quando na escola essa utilização não é prevista acaba-se por gerar ainda mais a exclusão educacional de uma parcela de alunos, ampliando, portanto, ainda mais o distanciamento dos que têm acesso a novas informações e possibilidades de aprendizagem dos que não possuem, ratificando a constituição da sociedade vigente como ressalta Martins:

Falar de cooperação num contexto cada vez mais capitalista, materialista, instrumentalista individualista e utilitarista pode até parecer estranho, mas é preciso lutar pelo desenvolvimento dessa capacidade. Afinal, os desafios relacionados às sociedades complexas e plurais exigem soluções coletivas e não individualistas. Daí a importância de o ambiente educacional criar espaços 
e práticas capazes de estimular a participação ativa dos educandos em sua própria formação. Isso significa, [...] mostrar que eles precisam aprender a dividir essas tecnologias. Não se trata de pegar computadores, celulares e proibir o seu uso. Mas de limitar e de ofertar a oportunidade de aprender a usar essas [...] tecnologias de maneira cooperativa e não individualista (20|9, p. | I).

Nesse sentido, enfatiza-se ainda mais a necessidade da oferta da formação continuada dos professores abordar as fragilidades deixadas na formação inicial, para que o processo de ensino permita um ambiente propício ao desenvolvimento da autonomia e participação ativa dos alunos. Dessa maneira, faz-se necessário que a formação do professor para o uso pedagógico das TDIC ocorra na ação docente, de forma reflexiva, crítica sobre esta ação.

Cardoso (20II) evidencia ainda que as mudanças na forma de comunicação com o uso das TDIC transformaram o consumo midiático não só nos aspectos de entretenimento, informações e notícias, como na dimensão científica. E, consequentemente, no sistema de ensino, que se baseia na comunicação do conhecimento produzido. Assim sendo, a mudança comunicacional também afeta e cria alterações de caráter cognitivo, ou seja, produz tensões dentro do sistema educacional, por exemplo, de um lado a palestra expositiva de outro a palestra interativa, ou até mesmo atendimento presencial versus a distância em tempo real.

Percebe-se, portanto, segundo Peixoto e Araújo (20 I 2), que o uso da tecnologia e seus efeitos na educação estão intimamente interligados com a forma com que esta é apropriada pelos sujeitos que farão uso, pois ela pode apenas promover um ensino voltado para a transmissão e instrução, ou pode partir de um ensino que promova uma aprendizagem autônoma e colaborativa. Assim como, pode ser determinada por uma visão otimista, enxergando as possibilidades advindas da tecnologia para alguns aspectos de melhoria de vida, ou uma visão pessimista apontando a tecnologia como uma forma de isolamento e dominação das máquinas.

Porém, é notório, como apontam Prado e Rocha (2018) que as TDIC proporcionam novas formas de comunicação, representação do conhecimento além da propagação das informações por meio de diferentes linguagens e mídias. Entretanto, toda a utilização exige uma nova compreensão quanto às necessidades presentes no processo ensino aprendizagem, e demandam reflexões sobre as práticas pedagógicas, o currículo e a escola como um todo.

Nesse horizonte, como assevera Baranauskas (20l8), considerando que a inclusão pressupõe transformações no contexto escolar, e fora dele, construídas e compartilhadas pelas partes envolvidas, logo a tecnologia digital pela comunidade escolar deve ser empregada como um instrumento de transformação social.

De certa maneira, a partir da implantação do atendimento remoto com as aulas não presenciais devido a COVID-19 ficou evidente a necessidade de se investir na formação e na capacitação dos profissionais da educação, sobretudo, dos gestores, pedagogos e professores. Outro fato que ficou 
evidente é a desigualdade no acesso às tecnologias. Isso tudo leva a reflexão sobre o quanto estamos distantes de um cenário ideal de acesso e de utilização das TDIC, na sociedade em geral, e mais especificamente, nas escolas como forma de enriquecimento do trabalho pedagógico. Entretanto, suscitou também, o quanto não é mais possível retroceder nesse processo.

Se por um lado, havia resistências ou preocupações quanto à substituição, ou superação da figura do professor com o uso das TDIC, todo este cenário conduziu-nos ao entendimento de que as tecnologias apenas são meios que possibilitam, de maneira ainda mais efetiva, a comunicação, a interação e a busca por novas informações e conhecimentos. Dessa forma, o direcionamento, a mediação e as abordagens dos professores sempre terão espaço para efetivação do processo de ensino e aprendizagem. Saber utilizálas permite criar novas e estimulantes possibilidades.

Entretanto, não depende apenas na vontade dos professores, diretores e pedagogos o uso das TDIC ser efetivado nas escolas de forma satisfatória. São necessários investimentos tanto em equipamentos quanto em formação continuada por parte do Governo, a fim de proporcionar o letramento digital dos professores e, consequentemente, dos alunos. Isso, no intuito de vivenciar uma educação equitativa e de qualidade para todos. Afinal, esta crise gerada pela pandemia mostrou a necessidade veemente da educação avançar para além das estratégias comumente utilizadas, priorizando metodologias e recursos mais condizentes com a geração atendida e as realidades sociais. É preciso trabalhar para a emancipação dos sujeitos por intermédio da educação.

\section{CONSIDERAÇÕES FINAIS}

As TDIC estão cada vez mais presentes na vida de todos os indivíduos. Contudo, se os avanços tecnológicos ocorrem de maneira vertiginosa, por outro lado os avanços sociais, que possam permitir o acesso de todos às tecnologias digitais não são tão céleres como deveriam.

No campo educacional o advento das TDIC como ferramentas de aporte pedagógico também ocorre de modo lento e pouco adequado frente às necessidades da sociedade com relação ao letramento digital. Os motivos são variados: infraestrutura deficitária das instituições de ensino, falta de materiais e equipamentos tecnológicos, além da necessidade de formação inicial e continuada para os educadores, preparando-os e capacitando-os melhor para essas novas demandas.

A implantação de aulas remotas imposta pela necessidade do isolamento social, devido à pandemia da COVID- 19 evidenciou as marcantes e históricas desigualdades sociais, especialmente pelas dificuldades de acesso à internet e aos recursos tecnológicos, como um computador e/ou um smartphone de milhões de alunos em todo Brasil, assim como inúmeros desafios e obstáculos dos professores no processo de aulas não presenciais, sobretudo pela dificuldade de acesso e domínio das ferramentas tecnológicas. 
Se por um lado a utilização das TDIC mostrou-se como possibilidade para a manutenção do calendário escolar, em virtude das características de interação possíveis entre professores e alunos, de outro, desvelou mazelas quanto ao acesso e conhecimento superficial para sua efetiva utilização, e em algumas situações acarretou ainda maior desigualdade educacional.

Portanto, diante do exposto, evidencia-se a necessidade de repensar políticas públicas e educacionais que garantam aos alunos e educadores melhores condições para a utilização das TDIC no processo de ensino e aprendizagem. Com o propósito de atender as demandas da sociedade atual, em prol de uma educação com mais igualdade de direitos e equidade nas condições de acesso. Permitindo aos professores as possibilidades de mediação das aprendizagens, e aos alunos, maior autonomia frente a sua formação, estimulando a permanência e êxito no processo educacional e consequentemente emancipação intelectual e social.

\section{REFERÊNCIAS}

ALMEIDA, Maria Elizabeth Bianconcini de. Tecnologias e formação de professores: relações entre o sujeito e a experiência no decorrer da história. In: VALENTE, José Armando; Freire, Fernanda Maria Pereira; ARANTES, Flávia Linhalis (Orgs.). Tecnologia e educação: passado, presente e o que está por vir. Campinas: NIED/UNICAMP, 2018. p. 99-121. (BRASIL, 2002

ALTENFELDER, Anna Helena et al. Ensinar e aprender no mundo digital: fundamentos para a prática pedagógica na cultura digital. São Paulo: Cenpec, 201 I. 33 p.

ALTOÉ, Anair; FUGIMOTO, Sonia Maria Andreto. Computador na educação e os desafios educacionais. In: IX Congresso Nacional de Educação - EDUCERE. III Encontro Sul-Brasileiro de Psicopedagogia, 2009. Curitiba. Anais [...]. Curitiba: PUCPR, 2009. p. I63- 175. Disponível em: https://educere.bruc.com.br/arquivo/pdf2009/1919 1044.pdf. Acesso em: 19 jul. 2020.

BARANAUSKAS, Maria Cecília C. Tecnologia e cenários de aprendizagem: uma abordagem sistêmica e socio-situada. In: VALENTE, José Armando; Freire, Fernanda Maria Pereira; ARANTES, Flávia Linhalis (Orgs.). Tecnologia e educação: passado, presente e o que está por vir. Campinas: NIED/UNICAMP, 2018. p. $42-64$.

BARRETO, Raquel Goulart. Tecnologia e educação: trabalho e formação docente. Educ. Soc., Campinas, v. 25, n. 89, p. I |81-1201, set./dez. 2004.

BEZERRA, Irvin Soares. Inclusão digital como forma de cidadania e a lei de acesso à informação. Env. Smoke, v. I, n. I, p. I48-161, ago. 2018.

BRANCO, Emerson Pereira; ZANATTA, Shalimar Calegari; BRANCO, Alessandra Batista de Godoi; NAGASHIMA, Lucila Akiko. A implantação da Base Nacional Comum Curricular no contexto das políticas neoliberais. Curitiba: Appris, 2018. 134 p.

BRASIL. Resolução CNE/CP No I , Diretrizes Curriculares Nacionais para a Formação de Professores da Educação Básica, em nível superior, curso de licenciatura, de graduação plena. Brasília: Ministério de 
Educação, 2002. Disponível em: http://portal.mec.gov.br/seesp/arquivos/pdf/res I 2.pdf. Acesso em: I8 jul. 2020.

BRASIL. Resolução CNE/CP N² 2, Diretrizes Curriculares Nacionais para a formação inicial em nível superior (cursos de licenciatura, cursos de formação pedagógica para graduados e cursos de segunda licenciatura) e para a formação continuada. Brasília: Ministério de Educação, 20I 5. Disponível em: http://portal.mec.gov.br/index.php?option=com_docman\&view=download\&alias= 17719 -res-cne-cp002-030720 I 5\&category slug=julho-20 I5-pdf\&ltemid=30192. Acesso em: 12 set. 2020.

BRASIL. Lei N 13.4I5, de 16 de fevereiro de 2017.

BRASIL. Base Nacional Comum Curricular: educação é a base. Brasilia: MEC, 20 I 8. 595 p.

BRASIL. Resolução CNE/CP Nº 2, Diretrizes Curriculares Nacionais para a Formação Inicial de Professores para a Educação Básica e institui a Base Nacional Comum para a Formação Inicial de Professores da Educação Básica (BNC-Formação). Brasilia: Ministério de Educação, 20। 9. Disponível em: http://portal.mec.gov.br/docman/dezembro-2019-pdf/I3595I-rcp002-19/file. Acesso em: I 2 set. 2020

BRASIL. Parecer CNE/CP N 05/2020. Brasília: Ministério de Educação/Conselho Nacional de Educação, 2020a. Disponível em:

http://portal.mec.gov.br/index.php?option=com_docman\&view=download\&alias $=14501$ I 20\&category slug=marco-2020-pdf\&ltemid =30192. Acesso em: 12 set. 2020

BRASIL. Parecer CNE/CP Nº9/2020. Brasília: Ministério de Educação/Conselho Nacional de Educação, 2020b. Disponível em:

http://portal.mec.gov.br/index.php?option =com docman\&view=download\&alias $=14704$ I pcp00920\&category slug =junho-2020-pdf\&ltemid =30192. Acesso em: 12 set. 2020

BRASIL. Parecer CNE/CP No I I/2020. Brasilia: Ministério de Educação/Conselho Nacional de Educação, 2020c. Disponível em:

http://portal.mec.gov.br/index.php?option $=$ com docman\&view $=$ download\&alias $=|4839|$-pcp0 | | 20\&category slug=julho-2020-pdf\&Itemid=30192. Acesso em: 12 set. 2020

CAETANO, Luís Miguel Dias. Tecnologia e Educação: quais os desafios? Revista do Centro de Educação, v. 40, n. 2, p. 295-309, maio-agosto, 2015.

CARDOSO, Gustavo. Mudança social em rede. In: Centro Ruth Cardoso (Org.). Políticas sociais ideias e prática. São Paulo: Moderna, 201 I. p. 219-258.

CARVALHO, Maria Regina Viveiros. Perfil do professor da educação básica. Brasília: INEP, 20I 8. 67 p.

FREITAS, Maria Teresa. Letramento digital e formação de professores. Educação em Revista. Belo Horizonte, v. 26, n. 3, p. 335-352, dez. 2010.

IBGE. Instituto Brasileiro de Geografia e Estatística. Acesso à Internet e à televisão e posse de telefone móvel celular para uso pessoal 2018. 2020. Disponível em:

https://biblioteca.ibge.gov.br/visualizacao/ivros/liv101705_informativo.pdf. Acesso em: 25 maio 2020.

INEP. Instituto Nacional de Estudos e Pesquisas Educacionais Anísio Teixeira. Censo Nacional da Educação Básica - 2019. Brasília: INEP/MEC, 2020. 32 p.

LÉVY, Pierre. Cibercultura. Tradução de Carlos Irineu Costa. São Paulo: Editora 34, 1999. 25 I p. 
LIBÂNEO, José Carlos; OLIVEIRA, João Ferreira de; TOSCHI, Mirza Seabra. Educação escolar: políticas, estrutura e organização. 10. ed. São Paulo: Cortez, 2012. 544 p.

MARTINS, Maurício Rebelo. Educação e tecnologia: a crise da inteligência. Educação (UFSM), v. 44, p. $1-14,2019$

MOREIRA, Antonio Flavio Barbosa; KRAMER, Sonia. Contemporaneidade, educação e tecnologia. Educ. Soc., Campinas, v. 28, n. 100 - Especial, p. 1037-1057, out. 2007.

MOREIRA, Carla. Letramento digital: do conceito à prática. In: II Simpósio Internacional de Ensino da Língua Portuguesa - SIELP, v. 2, n. I, 20I2, Uberlândia. Anais [...]. Uberlândia: EDUFU, 20I2. p. I - 15. Disponível em: http://www.ileel.ufu.br/anaisdosielp/?page id=3983. Acesso em: 23 jun. 2020.

OLIVEIRA, João Batista Araujo e. Repensando a educação brasileira: o que fazer para transforma nossas escolas. São Paulo: Salta, 2015. 192 p.

PEIXOTO, Joana; ARAÚJO, Cláudia Helena dos Santos. Tecnologia e educação: algumas considerações sobre o discurso pedagógico contemporâneo. Educ. Soc., Campinas, v. 33, n. I I 8, p. 253-268, jan.mar. 2012.

PRADO, Maria Elisabette Brisola Brito; ROCHA, Ana Karina de Oliveira. Formação continuada do professor no contexto da programação computacional. In: VALENTE, José Armando; Freire, Fernanda Maria Pereira; ARANTES, Flávia Linhalis (Orgs.). Tecnologia e educação: passado, presente e o que está por vir. Campinas: NIED/UNICAMP, 2018. p. I49-163.

SILVA, Roberta Maria Lobo da. Tecnologia e desafios da educação brasileira contemporânea. Trab. Educ. Saúde. v. 6, n. I, p. 29-50, 2008.

SILVA, Solimar Patriota. Letramento digital e formação de professores na era da web 2.0: o que, como e por que ensinar? Hipertextus Revista Digital, n. 8, jun. 2012.

TAROUCO, Liane Margarida Rockenbach. Competências digitais dos professores. In: CETIC-BR. Tic educação: pesquisa sobre o uso das tecnologias de informação e comunicação nas escolas brasileiras. São Paulo: Comitê Gestor da Internet no Brasil, 2019. p. 33-44.

VALENTE, José Armando. Inovação nos processos de ensino e de aprendizagem: o papel das tecnologias digitais. In: VALENTE, José Armando; FREIRE, Fernanda Maria Pereira; ARANTES, Flávia Linhalis (Orgs.). Tecnologia e educação: passado, presente e o que está por vir. Campinas: NIED/UNICAMP, 2018. p. 17-4I.

VIERO, Verônica Crestani; SILVEIRA, Ada Cristina Machado da. Apropriação de tecnologias de informação e comunicação no meio rural brasileiro. Cadernos de Ciência \& Tecnologia, Brasília, v. 28, n. I, p. 257-277, jan./abr. 201 I. 


\section{COMO CITAR ESSE ARTIGO}

\section{Associação Brasileira de Normas Técnicas (ABNT)}

BRANCO, Emerson Pereira; ADRIANO, Gisele; ZANATTA, Shalimar Calegari. Educação e TDIC: contextos e desafios das aulas remotas durante a pandemia da COVID- 19. Debates em Educação, Maceió, v. 12, p. 328-350, dez. 2020. ISSN 2175-6600. Disponível em:

https://www.seer.ufal.br/index.php/debateseducacao/article/view//07/2. Acesso em: dd mmm. aaaa.

\section{American Psychological Association (APA)}

Branco, E., Adriano, G., \& Zanatta, S. (2020). Educação e TDIC: contextos e desafios das aulas remotas durante a pandemia da COVID-19. Debates em Educação, 12(Esp2), 328-350. doi: https://doi.org/10.28998/2175-6600.2020v I2nEsp2p328-350 